\title{
Use of Response Shift to Improve Agreement between Patient- Reported and Performance-Based Outcomes in Knee Patients
}

Shelby Baez, PhD, ATC*; Johanna M. Hoch, PhD, ATC $\dagger$; Carl Mattacola, PhD, ATC, FNATA $\ddagger$; Philip Gribble, PhD, ATC, FNATA $†$, Jennifer S. Howard, PhD, ATC**

*Michigan State University, East Lansing, Ml; †University of Kentucky, Lexington, KY; $\ddagger$ University of North Carolina at Greensboro, Greensboro, NC; **Appalachian State University, Boone, NC

\begin{abstract}
The purpose of this study was to determine whether the implementation of performance-based tasks (PBTs) prior to completion of patient-reported outcome measures (PROs) would create a change, or a response shift, in PROs in patients with knee injuries. A randomized controlled trial was implemented to examine the effectiveness of a response-shift based interventions to enhance the correlation between PBTs and PROs. Participants $(n=20)$ were knee-injured patients who were removed from activity for a minimum of 1-week. Participants were randomly assigned to complete PBTs (intervention) or to watch videos detailing an injury prevention program (control). The International Knee Documentation Committee Subjective Form (IKDC) and the Knee Injury and Osteoarthritis Outcome Score Recreational and Sports Subscale (KOOSsports) were completed both pre- and post-testing. The independent variable was Group. Dependent variables included raw change scores and absolute change scores on the IKDC and KOOSsports. Mann-Whitney $U$ tests were used to examine between Group differences. Changes in PRO scores were not considered statistically significant or clinically meaningful (IKDC Raw $p=0.14$, Absolute $p=0.74$; KOOSsports Raw $p=0.85$ Absolute $p=0.32$ ). Implementation of PBTs prior to PROs did not induce a response shift. PROs may better evaluate symptoms and/or confidence in a patient, while PBTs evaluate physical function.
\end{abstract}

\section{Key Phrases}

Patient-reported outcomes, clinician-rated outcomes, functional testing

\section{Correspondence}

Dr. Shelby Baez, Michigan State University, 308 W Circle Drive 27P, East Lansing, MI

48824.

E-mail: baezshel@msu.edu

\section{Full Citation}

Baez S, Hoch JM, Mattacola C, Gribble P, Howard JS. Use of response shift to improve agreement between patient-reported and performance-based outcomes in knee patients. Clin Pract Athl Train. $2021 ; 4(1)$ : 24-35. https://doi.org/10.31622/2021/0004.1.4.

Submitted: July 30, 2020 Accepted: February 22, 2021.

Copyright (C) by Indiana State University All rights reserved. ISSN Online 2577-8188

\section{INTRODUCTION}

A fter an injury, patients often seek medical treatment to resolve their injury. Whether that treatment is therapeutic rehabilitation, surgical interventions, or even just the application of ice, it is important to evaluate the effectiveness of the method of treatment. The assessment of health outcomes is a fundamental component of a clinician's duties, as it provides a basis to determine which treatments are more effective. ${ }^{1}$ Assessment of health outcomes also provides a foundation to determine whether a patient can return to their pre-injury levels of activity. ${ }^{1}$ In athletics, most often the goal is to return patients to their pre-injury status and back to full participation as quickly and safely as possible. Different evaluation techniques have been employed to assess a patient's health status and to determine whether a patient is able to return to sport. These different techniques often include disease-oriented, performance-based, and patient-oriented measures. ${ }^{2-4}$

Disease-oriented measures assess outcomes associated with impairments at the body function and structure level. ${ }^{2}$ These measures typically include testing or evaluating the involved tissue, such as the Lachman's maneuver or the KT-1000 device, to test the integrity of the ACL. ${ }^{2}$ Performance-based measures are typically closed-kinetic tasks that examine the patient's ability to perform functional tasks that will likely stress the involved structure.3-5 Frequently used lower extremity performance-based measures include the single-leg hop for distance, crossover 
hop, 6-metered timed hop, shuttle run, and star excursion balance test.2,6-8 Lastly, patient-oriented outcomes are used to determine the perceived limitations and restrictions, most often through the use of patient reported outcome measures (PROs). 9 While many reliable and valid measures exist for each type of outcome, the observed correlation between various types of outcome measures is often poor to moderate, at best. ${ }^{10,11}$ Specifically, performance-based measures and PROs have frequently been observed to be only low to moderately correlated among knee-injured patients. 10,11

It has been theorized that failure to provide a frame of reference for patients to answer questions on PROs has led to the disagreement between PROs and performance-based measures. 10 Patients may be asked to answer questions related to tasks that they have not performed since sustaining injury. ${ }^{12}$ Asking patients to complete questionnaires prior to completing functional testing may result in patients having an insufficient sample of experiences from which to self-evaluate their current function. As proposed by Logerstedt et al., ${ }^{13}$ if patients can be provided with a relevant sample of experiences to be used to evaluate their current function, then their perceived function may be more in line with their true physical performance. Anecdotally, it has been observed that patients tended to either underestimate or overestimate on PROs if completed prior to performance-based testing. 14 Fitzgerald et al. ${ }^{14}$ hypothesized that completing performance-based tasks prior to the completion of PROs allowed the participant an opportunity to self-evaluate the status of their knee, which provided more accurate ratings of knee function on the self-report surveys.

Inconsistencies between PROs and performancebased measures may be due to the varying frame of reference patients use to complete PROs. As a result, PROs may be influenced by a response shift phenomenon. Although primarily studied in ill and

Copyright $(\subset)$ by Indiana State University All rights reserved. ISSN Online 2577-8188 chronic disease patients, response shift can also be detected in individuals suffering from an orthopaedic injury. 15,16 Response shift is defined as a change in an individual's internal standards, values, or conceptualization of a construct when evaluating their health related quality of life. ${ }^{17} \mathrm{~A}$ response shift results in a change in one's selfevaluation either through recalibration, reconceptualization, or reprioritization. ${ }^{18}$ Recalibration refers to a person's change in their internal standards of measurement; reconceptualization refers to a change in definition of the target construct; and reprioritization refers to a change in an individual's internal values. ${ }^{18}$ If individuals are susceptible to these changes, then it may be possible to recalibrate and/or reconceptualize an individual's self-perceived function through the implementation of a performance-based assessment intervention. While the response shift phenomenon has been reported in orthopaedic cases ${ }^{15,16}$, use of this theory to optimize PROs has not been previously evaluated. Therefore, the purpose of this study was to examine the effect of testing order on PRO scores to determine if completing a performance-based assessment with the intent to provide a frame of reference for the individual prior to the administration of PROs would alter PRO scores in knee patients. We hypothesized that completion of performancebased assessments prior to PROs would lead to a greater change on PRO scores between pre-test and post-test when compared to a control group.

\section{PATIENTS}

Participants were between the ages of 14-40 and had been restricted due to a knee pathology from full participation in physical activity for at least 1 week prior to testing and had recently been cleared to return to full activity. Participants could have no other injuries besides their current knee injury affecting their sports participation status, and they must have reported having a pre-injury activity level of 5 or greater on the Tegner 
Physical Activity Assessment. ${ }^{20}$ Additionally, participants were excluded based on the following criteria: known balance disorders, not cleared to return to activity, not cleared to perform functional testing, scored below a 46 on the IKDC, failure to pass the pre-participation functional assessment screening, or cleared for activity $>$ two weeks at time of recruitment. As a precaution, participants who scored below a 46 on their pre-intervention IKDC were not permitted to continue in the study. A cut-off of 46 was chosen because this value represented the mean preoperative value for surgical knee patients in the University of Kentucky Patient Registry at the time of study development which suggested that the patient may not be able to safely complete the functional tasks required of the study.

\section{INTERVENTION}

Design

A randomized controlled trial was used for this study, with participants randomized into either a performance-based assessment intervention group or an educational control group (Figure 1). A block randomized design with random block sizes ranging from 2-6 participants was used to complete randomization. An independent third party generated the randomization scheme using a publicly available randomization generator (http://randomization.com/) and created blinded envelopes for subject allocation. Individuals in the performance-based assessment group completed a battery of functional tests, while those selected for the educational control group participated in a placebo intervention consisting of watching exercises from the FIFA $11+$ program. ${ }^{19}$ The intervention session lasted approximately 40 minutes for both groups. Both groups completed the International Knee Documentation Committee Subjective Knee Form (IKDC) and the Knee Injury and Osteoarthritis Outcome Score Sports and Recreation Subscale (KOOSsports) pre- and postintervention. All participants reviewed and signed

Copyright $(\subset)$ by Indiana State University All rights reserved. ISSN Online 2577-8188 an informed consent approved by the University of Kentucky IRB prior to study participation.

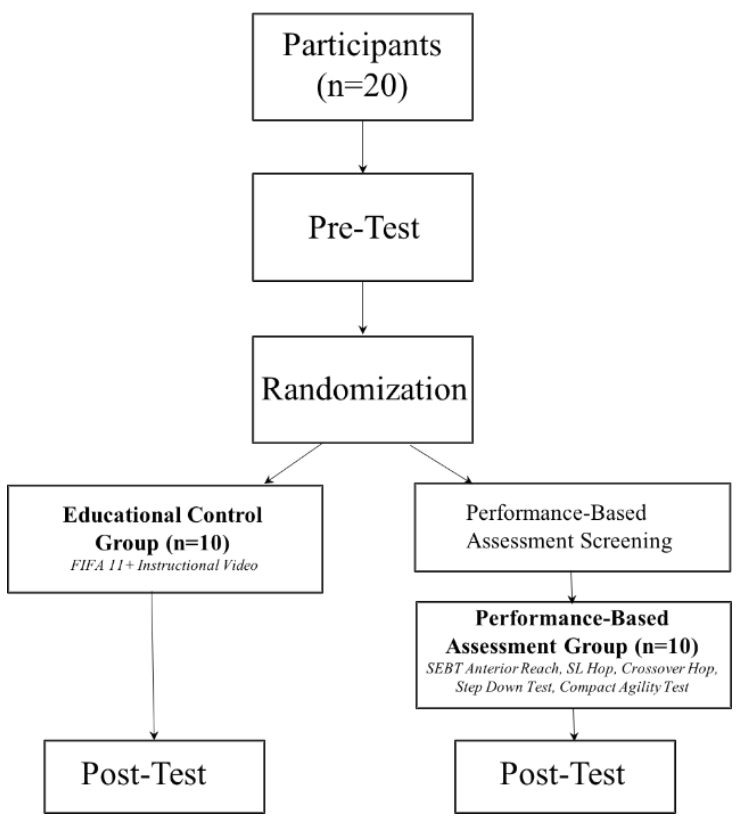

Figure 1. Study Design and Participant Allocation

Procedures

Participants completed a single testing session in a clinical laboratory lasting approximately $\mathbf{4 0}$ minutes. After informed consent and prior to randomization, all participants completed the IKDC and KOOSsports as pre-test assessments. Upon completion of pre-test PROs, the participant randomization envelope was opened, revealing group allocation.

\section{Educational Control Group}

Participants randomized into the educational control group were shown the FIFA11+19 exercise videos. The FIFA $11+$ is a sports and injury performance program that has been used extensively in the soccer community and beyond and, when implemented with high compliance, has been shown to reduce injury risk among soccer players. ${ }^{19,24-27}$ It was chosen as an educational control for this study, as the information provided in the video may be of some benefit to study participants, but was not anticipated to alter PRO 
scores. We chose to include a patient education component for the control group to reduce participant bias and provide some benefit to all participants. At the conclusion of the study, participants in both groups received a handout with links to the FIFA $11+19$ website as additional information to take with them. Following conclusion of the videos, the participants were again asked to complete the IKDC and KOOSsports.

\section{Performance-Based Assessment Screening}

As a precaution, prior to the completion of the performance-based tests, participants randomized to the performance-based assessment group completed a screening to verify the patient's eligibility/readiness to complete the performance-based tasks included in the study protocol. This screening consisted of a series of single-leg squats, side-to side-hops, and vertical hops. All participants were required to complete these tasks without pain, or any other symptoms.

Instrumentation

Those participants randomized into the performance-based assessment intervention group completed a 5-minute jogging warm-up followed by a battery of performance-based assessments. To ensure there was minimal fatigue and muscle soreness throughout the study, the order of tests was standardized for all participants and a three-minute rest period was provided between each test. For all assessments, participants were given ample time to practice each task, and for unilateral assessments the uninvolved limb was tested first.

\section{Star Excursion Balance Test (SEBT) - Anterior Reach $^{28}$}

The SEBT was used to assess dynamic balance. Participants maintained a single-leg stance on the involved limb while reaching for maximum distance in the anterior direction with the opposite limb. The participant's first toe was placed at the

Copyright $\left({ }^{\circ}\right.$ by Indiana State University All rights reserved. ISSN Online 2577-8188
0 point on the tape measure. Participants then reached as far anteriorly as possible and touched the tape measure while maintaining a single-leg stance. Participants were required to keep their hands on their hips and stance heel in contact with the ground. All participants were given the opportunity to complete 4 practice trials, followed by 3 test trials in the anterior direction only. The test was performed bilaterally with the uninvolved limb first. Reach distances were measured in centimeters and normalized by leg length. Leg length was measured from the anterior superior iliac spine to the base of the medial malleolus of the tibia. Mean reach distances were used to calculate limb symmetry index (LSI = (mean distance involved limb/mean distance uninvolved limb) x 100).

\section{Single-Leg Hop Tests ${ }^{29}$}

The Single-Leg Hop for Distance test is commonly used to measure power and confidence. The patient began standing on one leg and then jumped as far forward as possible landing on the same leg. The total distance hopped forward was recorded $(\mathrm{cm})$. The Crossover Hop for Distance also measures power and confidence in the tested leg. The patient began standing on one leg and then hopped as far as possible forward 3 times while alternating crossing over a 6-centimeters wide strip on the floor. The total distance hopped forward was recorded $(\mathrm{cm})$. Both hop tests were performed three times, with a 10 second recovery between trials. A successful trial included landing stable on the test leg and maintaining balance for three seconds. The trial was repeated if the participant landed with early touchdown of the contralateral leg, lost balance, touched the surrounding area, or included additional hops after landing. Mean hop distances were used to calculate limb symmetry index (LSI = [mean distance involved limb/mean distance uninvolved limb] x 100). The Single-Leg Hop for Distance and the Crossover Hop for Distance have previously been reported to be reliable and valid measures 
of functional performance, 30 and are routinely used clinically to evaluate recovery and readiness to return to sporting activity.

\section{Second Step-Down Test ${ }^{31}$}

Participants were asked to perform a step-down motion from a platform 8-inches high. Participants were instructed that contact with the floor should only be a brush and not be used to accelerate back onto the step, hands must remain on the hips, and to complete as many repetitions as possible within a single 30-second trial. Participants completed one 30-second test trial on each limb, with a 3-minute recovery time between test legs. ${ }^{31}$ Limb symmetry index was calculated using the following equation: ( $\mathrm{LSI}=$ [mean distance involved limb/mean distance uninvolved limb] x 100).

\section{Compact Agility Test (CAT)}

Participants completed an assessment of agility, quickness, and body control by completing a sprinting and shuffling task on a 4-meter path. The path was marked by tape and the individual performed the following tasks with their best effort. The testing procedure followed the pattern presented in Figure 2. This resulted in a total distance traversed of 20 meters. Participants completed a walk-through of the task to gain familiarity and then were asked to complete a submaximal effort of the task to ensure fluidity of the task. Additional submaximal trials were permitted if necessary, for the participants to feel comfortable with the test. The participants were then asked to complete two test trials at the highest speed with which they were comfortable. A two-minute rest period was given between test trials. Verbal cuing occurred from the investigator throughout the entire testing session of the CAT. The faster of the two trials was used as the CAT result for analysis. This test was designed to be completed in a small space, such as a doctor's office, and to provide patients with a sampling of experiences that involved sprinting, cutting/planting, and lateral movements.

Copyright $(\subset)$ by Indiana State University All rights reserved. ISSN Online 2577-8188

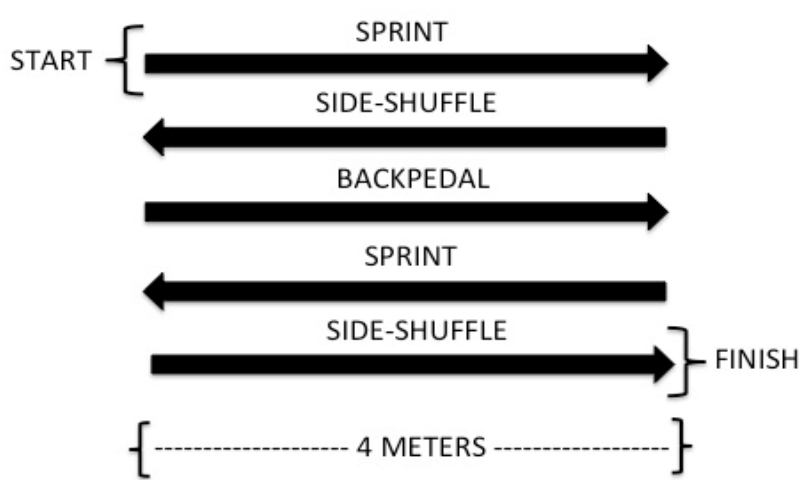

Figure 2. Compact Agility Test (CAT). Completed on 4metered pathway.

\section{OUTCOME MEASURES}

Following completion of the performance-based assessment battery, participants completed the post- IKDC and KOOSsports assessments. To avoid biasing PRO scores, participants did not receive scores on performance-based measures until post-test PROs were completed. Both the IKDC and KOOS are valid and reliable PROs used for individuals suffering from knee pathology. 21,22 The IKDC is a 20 -item outcome measure used to determine patient perceived function. The KOOSsports is a 5 -question subscale of the KOOS used to evaluate patient perceived function for activities such as running, cutting, and jumping. All PROs were collected and managed using Research Electronic Data Capture (REDCap) tools hosted at the XXX. REDCap is a secure, webbased application designed to support data capture for research studies. ${ }^{23}$

\section{Statistical Analysis}

Descriptive statistics were generated for all performance-based measures and PROs. To ensure that the randomization resulted in comparable groups, independent t-tests or MannWhitney $U$ tests were used to compare height, weight, age, and time between clearance to RTS and the data collection session between groups. To determine if participation in performancebased assessments resulted in a change in PRO

Clinical Practice in Athletic Training Volume 4 - Issue 1 - February 2021 
scores, Mann-Whitney $U$ tests were used to compare the raw change (post-test - pre-test) and absolute change (|post-test - pre-test|) between groups for both the IKDC and KOOSsports scores. ${ }^{15}$ Minimal detectable change (MDC) values were interpreted to identify clinically meaningful changes in the IKDC and KOOS sports scores.

\section{RESULTS}

A total of 20 participants were enrolled into the study (performance-based assessment $n=10$, educational control $n=10$ ). Participants' demographic information are presented in Table 1. Eleven out of 20 of the participants were cleared to return to activity following ACLreconstruction. Two other patients were postsurgical (medial meniscal allograft transplantation and meniscectomy). The remaining nine participants suffered from IT band friction syndrome $(n=1)$, Morel-Lavalle lesion $(n=1)$, lateral collateral ligament sprain $(n=2)$, articular cartilage damage $(n=2)$, meniscal tear $(n=2)$, or patellofemoral pain syndrome $(n=1)$. Participants were tested a median of 1.5 days from physician and/or other healthcare professional's clearance to return to sport. There were no differences in demographics between the two groups. Average pre-test, post-test, and change scores for the performance-based assessment group and educational control group are presented in Table 2. Descriptive statistics for performance-based measures are presented in Table 3. No significant differences were observed between groups when comparing raw change scores and absolute change scores for the IKDC and KOOSsports (IKDC Raw Change $p=0.14$, Absolute Value $p=$ 0.74; KOOSsports Raw Change $p=0.85$ Absolute Value $p=0.32$ ) (Table 2).

\section{DISCUSSION}

To our knowledge, this is the first study to use a response shift theory-based intervention to enhance the agreement between performancebased measures and PROs. The aim of this study

Copyright $\left({ }^{\circ}\right.$ by Indiana State University All rights reserved. ISSN Online 2577-8188 was to determine whether testing order would improve the agreement between performancebased measures and scores on the IKDC and KOOSsports. However, our results did not support our hypothesis as we observed that providing a specific frame of reference from which patients could evaluate themselves did not result in systematic changes in PRO scores. These results suggest that PROs can be implemented before or after performance-based testing during the rehabilitation of knee patients and support the use of both PROs and performance-based testing in clinical practice.

While no between group differences were identified, some participants included in this study did increase or decrease their score at the posttest despite their ability to successfully complete performance-based tasks with high LSIs (Table 3). In accordance with Howard et al., 20 the present study also observed evidence that a response shift may occur on a patient-by-patient basis after knee injury. Fifty percent of the participants randomized into the performance-based assessment group reported lower scores on the IKDC at the post-test (Table 4). This suggests that participants overestimated their function prior to completion of functional testing. Concerns for overestimation on PROs in patients after $\mathrm{ACL}$ reconstruction has been previously postulated.14 While evaluating decision-making criteria for return to sport after $A C L$ reconstruction, Fitzgerald et al. ${ }^{14}$ altered their methods of administering PROs to their patients to accommodate anecdotal observations involving testing order.14 Investigators reported observing that patients tended to overestimate or underestimate on selfreport scores if hop tests were performed after the completion of PROs. While not statistically or clinically meaningful between groups, the results from the present study further support this observation that individual patients may shift their responses on PROs due to their experience while engaging in the performance-based assessments.

Clinical Practice in Athletic Training Volume 4 - Issue 1 - February 2021 
Table 1. Participant Demographics

\begin{tabular}{|c|c|c|c|c|}
\hline Measure & $\begin{array}{c}\text { Performance } \\
\text { Group } \\
(n=10)\end{array}$ & $\begin{array}{c}\text { Educational } \\
\text { Control }(n=10)\end{array}$ & $\begin{array}{l}\text { Total } \\
(n=20)\end{array}$ & P-Value \\
\hline & \multicolumn{3}{|c|}{ Mean (SD) } & \\
\hline Height (cm) & $177.24(9.43)$ & $173.00(11.27)$ & $175.12(10.32)$ & $0.37^{*}$ \\
\hline Weight (kg) & $80.40(18.70)$ & $82.20(17.22)$ & $81.30(17.52)$ & $0.83^{*}$ \\
\hline \multirow{2}{*}{$\begin{array}{l}\text { Tegner Score (Current } \\
\text { Level) }\end{array}$} & $8.00(1.70)$ & $8.00(1.42)$ & $8.00(1.52)$ & $1.00 *$ \\
\hline & \multicolumn{3}{|c|}{ Median (IQR) } & \\
\hline Age (years) & $20.00(3.00)$ & $20.50(4.00)$ & $20.00(3.00)$ & $0.63^{\#}$ \\
\hline $\begin{array}{l}\text { Time from Clearance } \\
\text { (days) }\end{array}$ & $6.50(7.00)$ & $1.00(3.00)$ & $1.50(7.00)$ & $0.09 \#$ \\
\hline $\begin{array}{l}\text { Tegner Score (Before } \\
\text { Injury) }\end{array}$ & $9.00(3.00)$ & $9.00(3.00)$ & $9.00(2.00)$ & $0.39 \#$ \\
\hline
\end{tabular}

Table 2. Patient-Reported Outcome Measures Pre-Test, Post-Test, and Change Scores

\begin{tabular}{|c|c|c|c|c|}
\hline Measure & $\begin{array}{l}\text { Performance- } \\
\text { Based } \\
\text { Assessment } \\
\text { Median (IQR) }\end{array}$ & $\begin{array}{c}\text { Educational } \\
\text { Control Median } \\
\text { (IQR) }\end{array}$ & $\begin{array}{l}\text { Total } \\
\text { Median } \\
\text { (IQR) }\end{array}$ & $\begin{array}{c}\text { Mann- } \\
\text { Whitney U } \\
\text { Test P-Value }\end{array}$ \\
\hline IKDC Pre-Test & $87.94(11.78)$ & $88.51(22.13)$ & $87.94(13.21)$ & 0.57 \\
\hline $\begin{array}{l}\text { IKDC Post-Test } \\
\text { KOOS }_{\text {sports Pre-Test }} \\
\text { KOOS }_{\text {sports }} \text { Post-Test }\end{array}$ & $\begin{array}{l}87.36(15.80) \\
90.00(26.00) \\
90.00(26.00)\end{array}$ & $\begin{array}{l}89.66(23.56) \\
92.50(41.00) \\
92.50(41.00)\end{array}$ & $\begin{array}{l}87.94(15.23) \\
90.00(29.00) \\
90.00(29.00)\end{array}$ & $\begin{array}{l}0.35 \\
1.00 \\
0.91\end{array}$ \\
\hline$\Delta$ IKDC Raw Change & $-0.57(3.16)$ & 0.01 (2.59) & $0.00(3.16)$ & 0.14 \\
\hline $\begin{array}{l}\Delta \text { IKDC Absolute } \\
\text { Value }\end{array}$ & $1.16(2.87)$ & $1.72(2.30)$ & $1.16(2.30)$ & 0.74 \\
\hline $\begin{array}{l}\Delta \text { KOOS }_{\text {sports }} \text { Raw } \\
\text { Change }\end{array}$ & $0.00(6.00)$ & $0.00(0.00)$ & $0.00(0.00)$ & 0.85 \\
\hline $\begin{array}{l}\triangle K^{\prime} O^{\prime} S_{\text {sports }} \text { Absolute } \\
\text { Value }\end{array}$ & $2.50(5.00)$ & $0.00(1.00)$ & $0.00(5.00)$ & 0.32 \\
\hline
\end{tabular}


Table 3. Outcomes of PROs change scores and performance-based testing demonstrating mean values and standard deviation (SD), and p-value

\section{Performance-Based Assessment Mean (SD)}

\begin{tabular}{lc}
\hline SEBT Anterior Reach & $99.22(4.90)$ \\
SL Hop for Distance LSI & $100.29(11.12)$ \\
Crossover Hop for Distance LSI & $95.91(13.66)$ \\
30 Second Step Down Task LSI & $96.50(11.71)$ \\
Compact Agility Test AVG & $10.13(1.57)$ \\
\hline *LSI = Limb Symmetry Index, SEBT = Start Excursion Balance Test, SL = Single Leg
\end{tabular}

Table 4. Individual Changes in PRO Scores Between Groups

\begin{tabular}{lcccc} 
& IKDC - PRE & IKDC - POST & KOOS $_{\text {sports }}$ PRE & KOOS $_{\text {sports }}$ - POST \\
\hline PBA & 91.95 & 91.96 & 100 & 100 \\
PBA & 89.66 & 89.66 & 90 & 90 \\
PBA & 51.72 & $41.38^{*}$ & 25 & $35^{\#}$ \\
PBA & 80.46 & $79.32^{*}$ & 85 & $80^{*}$ \\
PBA & 87.36 & $86.21^{*}$ & 75 & $70^{*}$ \\
PBA & 79.31 & $77.02^{*}$ & 90 & 90 \\
PBA & 78.16 & $73.57^{*}$ & 70 & $75^{\#}$ \\
PBA & 90.8 & $93.11^{\#}$ & 100 & $95^{*}$ \\
PBA & 90.8 & $91.96^{\#}$ & 100 & 100 \\
PBA & 88.51 & 88.51 & 100 & 100 \\
Control & 57.47 & $55.18^{*}$ & 55 & 55 \\
Control & 87.36 & 87.36 & 90 & $80^{*}$ \\
Control & 83.91 & $82.76^{*}$ & 90 & 90 \\
Control & 97.7 & 97.7 & 95 & 95 \\
Control & 78.16 & $80.46^{\#}$ & 60 & 60 \\
Control & 94.25 & $97.71^{\#}$ & 100 & 100 \\
Control & 40.23 & $42.53^{\#}$ & 35 & $40^{\#}$ \\
Control & 94.25 & 94.26 & 100 & 100 \\
Control & 100 & 100 & 100 & 100 \\
Control & 89.66 & $91.96^{\#}$ & 100 & 100 \\
\hline PBA Performan
\end{tabular}

PBA = Performance-Based Assessment, IKDC = International Knee Documentation Committee, KOOS $_{\text {sports }}=$ Knee Injury and Osteoarthritis Outcome Score Sports and Recreational Subscale * = decreased from pre to post test, \# = increased from pre to post test 
These results also highlight the importance of integration of a holistic approach to health outcome evaluation. Performance-based measures completed in this study provided information about the patient's strength, power, and agility. However, those tasks may only provide limited information about the patient's pain or confidence levels, particularly when performed in a controlled laboratory environment. Evaluation of a patient's confidence levels, and perception of function are just as important as evaluating the patient's strength, power, and agility. Providing a frame of reference did not alter median PRO scores, which suggests that these outcomes are measuring different aspects of health. This study adds to the growing body of literature supporting a multifaceted approach to outcome measurement to provide the most effective evaluation of patient care and progress.

Interestingly, 4 out of 10 participants in the educational control group exhibited increased scores on the IKDC at the post-test (Table 4). We hypothesize that these results may have occurred because of the influence of modeling on confidence. ${ }^{32}$ It has been demonstrated that vicarious experiences, or knowledge gained through observing the experiences of others, can enhance confidence. ${ }^{32}$ Participants in the educational control group may have increased their confidence to complete functional tasks through observation of individuals completing functional tasks in the FIFA $11+19$ videos. It is plausible that deficits in confidence were present in this sample at the time of testing as previous literature has demonstrated that lack of confidence is often reported as a barrier for return to sport after a sports-related knee injury. ${ }^{33}$ These results further support the integration of PROs into clinical practice. Use of the IKDC and KOOSsports may also provide insight into a patient's confidence levels prior to return to sport.

Limitations

Copyright $(\subset)$ by Indiana State University All rights reserved. ISSN Online 2577-8188
This study is not without limitations. Due to the nature of subject recruitment, researchers were unable to test most participants on the day of clearance. Participants, particularly those randomized into the performance-based assessment group, could have already been exposed to different stimuli that would represent a sample of experiences from which to answer PRO questions. Another limitation of this study is the small sample size $(n=20)$. However, despite the small sample size, given that only 1 participant demonstrated a change value exceeding minimal detectable change values for either PRO (IKDC = 6.7-20.5, KOOS sports $=12.2-7$ ), it is very clear that neither statistical nor clinical significance were likely to be reached for PROs even if more subjects had been enrolled.

\section{CLINICAL APPLICATION}

Evaluating health outcomes following rehabilitation is a fundamental component of a clinician's duties. This study demonstrated that providing a frame of reference for a highly trained athletic population did not significantly alter median PRO scores. Therefore, among knee patients it is acceptable to complete PROs either before or after completing performance-based measures. Furthermore, these outcome measures should not be used in substitute and both should be incorporated into clinical practice to provide a holistic approach to rehabilitation after knee injury. Patient reported outcome measures may be better suited at the evaluation of symptoms and/or confidence in a patient, while performance-based measures evaluate physical function in a controlled setting. Thus, it is important to utilize all forms of health outcome evaluation techniques to provide the best healthcare for our patients.

\section{Acknowledgements}

This publication was supported by the National Athletic Trainers' Association Research and Education Foundation Grant Number 15MGP002.

Clinical Practice in Athletic Training Volume 4 - Issue 1 - February 2021 
Its contents are the authors' sole responsibility and do not necessarily represent official National Athletic Trainers' Association Research and Education Foundation views.

The project described was supported by the National Center for Research Resources and the National Center for Advancing Translational Sciences, National Institutes of Health, through Grant 8UL1TR000117-02. The content is solely the responsibility of the authors and does not necessarily represent the official views of the NIH.

\section{REFERENCES}

1. Kaplan S. Outcome Measurement \& Management. Philadelphia, PA: F.A. Davis Company; 2007.

2. Neeb TB, Aufdemkampe G, Wagener JHD, Mastenbroek L. Assessing anterior cruciate ligament injuries: the association and differential value of questionnaires, clinical tests, and functional tests. J Orthop Sports Phys Ther. 1997;26(6):324-331. https://www.jospt.org/doi/10.2519/iospt.1 997.26.6.324.

3. Aalund PK, Larsen K, Hansen TB, Bandholm T. Normalized knee-extension strength or legpress power after fast-track total knee arthroplasty: which measure is most closely associated with performance-based and self-reported function? Arch Phys Med Rehabil. 2013;94(2):384-390. https://doi.org/10.1016/i.apmr.2012.09.0 31.

4. Sernert N, Kartus J, Koehler K, et al. Analysis of subjective, objective, and functional examination tests after anterior cruciate ligament reconstruction: a follow-up of 527 patients. Knee Surg Sports Traumatol Arthrosc. 1999;7(3):160-165. https://doi.org/10.1007/s001670050141.

5. Risberg MA, Ekeland A. Assessment of functional tests after anterior cruciate ligament surgery. J Orthop Sports Phys Ther.

Copyright () by Indiana State University All rights reserved. ISSN Online 2577-8188
1994;19(4):21 2-217.

https://doi.org/10.2519/iospt.1994.19.4.2 12.

6. Reiman M, Manske R. Functional Testing in Human Performance. Human Kinetics; 2009.

7. Stratford PW, Kennedy DM. Performance measures were necessary to obtain a complete picture of osteoarthritic patients. $J$ Clin Epidemiol. 2006;59(2):160-167. https://doi.org/10.1016/i.jclinepi.2005.07. 012.

8. Logerstedt D, Grindem H, Lynch A, et al. Single-legged hop tests as predictors of selfreported knee function after anterior cruciate ligament reconstruction: the Delaware-Oslo ACL cohort study. Am J Sports Med. 201 2;40(10):2348-2356. https://doi.org/10.1177/0363546512457 551.

9. Meadows KA. Patient-reported outcome measures: an overview. Br J Community Nurs. $2011 ; 16(3): 146-151$. https://doi.org/10.12968/bicn.2011.16.3.1 $\underline{46}$.

10. Maly MR, Costigan PA, Olney SJ. Determinants of self-report outcome measures in people with knee osteoarthritis. Arch Phys Med Rehabil. 2006;87(1):96-104. https://doi.org/10.1016/i.apmr.2005.08.1 10.

1 1. Mizner RL, Petterson SC, Clements KE, Zeni JA, Jr., Irrgang JJ, Snyder-Mackler L. Measuring functional improvement after total knee arthroplasty requires both performance-based and patient-report assessments: a longitudinal analysis of outcomes. J Arthroplasty. 2011 ; 26(5):728737.

https://dx.doi.org/10.1016\%2Fi.arth.2010. 06.004 .

12. Noyes FR, Barber SD, Mooar LA. A rationale for assessing sports activity levels and limitations in knee disorders. Clini Orthop Relat Res. 1989(246):238-249. 
13. Logerstedt D, Di Stasi S, Grindem H, et al. Self-reported knee function can identify athletes who fail return-to-activity criteria up to 1 year after anterior cruciate ligament reconstruction: A Delaware-Oslo $\mathrm{ACL}$ cohort study. J Orthop Sports Phys Ther.

2014;44(12):914-923. https://doi.org/10.2519/iospt.2014.4852.

14. Fitzgerald GK, Axe MJ, Snyder-Mackler L. A decision-making scheme for returning patients to high-level activity with nonoperative treatment after anterior cruciate ligament rupture. Knee Surg Sports Traumatol Arthrosc. 2000;8(2):76-82. https://doi.org/10.1007/s001670050190.

15. Howard JS, Mattacola CG, Mullineaux DR, English RA, Lattermann C. Influence of response shift on early patient-reported outcomes following autologous chondrocyte implantation. Knee Surg Sports Traumatol Arthrosc. 2014;22(9):2163-2171. https://doi.org/10.1007/s00167-0132654-1.

16. Balain B, Ennis O, Kanes G, et al. Response shift in self-reported functional scores after knee microfracture for full thickness cartilage lesions. Osteoarthritis Cartilage.

2009; 17(8): 1009-1013. https://doi.org/10.1016/i.joca.2009.02.00 7.

17. Schwartz CE, Sprangers MA. Methodological approaches for assessing response shift in longitudinal health-related quality-of-life research. Social Sci Med. (1982). 1999;48(11):1531-1548. https://doi.org/10.1016/s02779536(99)00047-7.

18. Sprangers MA, Schwartz CE. Integrating response shift into health-related quality of life research: a theoretical model. Social Sci Med. (1982). 1999;48(11):1507-1515. https://doi.org/10.1016/s0277. 9536(99)00045-3.

19. Soligard T, Myklebust G, Steffen K, et al. Comprehensive warm-up programme to prevent injuries in young female footballers: cluster randomised controlled trial. BMJ. 2008;337:a2469. https://doi.org/10.1136/bmi.a2469.

20. Tegner Y, Lysholm J. Rating systems in the evaluation of knee ligament injuries. Clin Orthop Relat Res. 1985; 198:43-49.

21. Irrgang JJ, Anderson AF, Boland AL, et al. Development and validation of the International Knee Documentation Committee Subjective Knee Form. Am J Sports Med. $2001 ; 29(5): 600-613$. https://doi.org/10.1177/0363546501029 0051301.

22. Roos EM, Roos HP, Lohmander LS, Ekdahl C, Beynnon BD. Knee injury and osteoarthritis outcome score (KOOS)-development of a self-administered outcome measure. $J$ Orthop Sports Phys Ther. 1998;28(2):88-96. https://doi.org/10.2519/iospt.1998.28.2.8 8.

23. Harris PA, Taylor R, Thielke R, Payne J, Gonzalez N, Conde JG. Research electronic data capture (REDCap)—a metadata-driven methodology and workflow process for providing translational research informatics support. J Biomed Inform. 2009;42(2):377381.

https://doi.org/10.1016/i.jbi.2008.08.010.

24. Owoeye OBA, Akinbo SRA, Tella BA, Olawale OA. Efficacy of the FIFA $11+$ warm-up programme in male youth football: a cluster randomised controlled trial. I Sports Sci Med. 2014;13(2):321-328.

25. Longo UG, Loppini $M$, Berton A, Marinozzi A, Maffulli $N$, Denaro V. The FIFA $11+$ program is effective in preventing injuries in elite male basketball players: a cluster randomized controlled trial. Am J Sports Med. 2012;40(5):996-1005. https://doi.org/10.1177/0363546512438 761.

26. Steffen K, Emery CA, Romiti $M$, et al. High adherence to a neuromuscular injury prevention programme (FIFA $11+$ ) improves

Clinical Practice in Athletic Training Volume 4 - Issue 1 - February 2021 
functional balance and reduces injury risk in Canadian youth female football players: a cluster randomised trial. $\mathrm{Br} J$ Sports Med.

2013;47(12):794-802.

https://doi.org/10.1136/bisports-2012091886.

27. Grooms DR, Palmer T, Onate JA, Myer GD, Grindstaff T. Soccer-specific warm-up and lower extremity injury rates in collegiate male soccer players. J Athl Train.

2013;48(6):782-789.

https://doi.org/10.4085/1062-605048.4.08.

28. Gribble PA, Hertel J, Plisky P. Using the Star Excursion Balance Test to assess dynamic postural-control deficits and outcomes in lower extremity injury: a literature and systematic review. J Athl Train.

2012;47(3):339-357. https://doi.org/10.4085/1062-605047.3.08.

29. Noyes FR, Barber SD, Mangine RE. Abnormal lower limb symmetry determined by function hop tests after anterior cruciate ligament rupture. Am J Sports med. 1991;19(5):513518.

https://doi.org/10.1177/0363546591019 00518.

30. Munro AG, Herrington LC. Between-session reliability of four hop tests and the agility $T$ test. J Strength Cond Res. 2011 ;25(5): 1470-

1477.

https://doi.org/10.1519/isc.0b013e3181d 83335.

31. Loudon JK, Wiesner D, Goist-Foley HL, Asjes C, Loudon KL. Intrarater reliability of functional performance tests for subjects with patellofemoral pain syndrome. J Athl Train. 2002;37(3):256-261.

32. Bandura A. Self-efficacy: toward a unifying theory of behavioral change. Psychol Rev. 1977;84(2):191. https://psycnet.apa.org/doi/10.1037/003 3-295X.84.2.191.
33. Burland JP, Toonstra J, Werner JL, Mattacola CG, Howell DM, Howard JS. Decision to return to sport after anterior cruciate ligament reconstruction, part I: a qualitative investigation of psychosocial factors. J Athl Train. 2018;53(5):452-463. https://doi.org/10.4085/1062-6050-31316. 